\title{
Trocas gasosas e balanço de carboidratos em plantas de cana-de-açúcar sob condições de estresses radiculares
}

\author{
Cristina Rodrigues Gabriel Sales (1); Rafael Vasconcelos Ribeiro (2); Daniela Favero São \\ Pedro Machado (1); Ricardo Silverio Machado (3); Verónica Lorena Dovis (4); Ana Maria \\ Magalhães Andrade Lagôa $\left(2^{*}\right)$
}

(') Instituto Agronômico (IAC), Programa de Pós Graduação em Agricultura Tropical e Subtropical, Av. Barão de Itapura, 1481, 13020-970 Campinas (SP), Brasil.

(2) IAC, Centro de Pesquisa e Desenvolvimento de Ecofisiologia e Biofísica, Laboratório de Fisiologia Vegetal "Coaracy M. Franco", 13020-970 Campinas (SP), Brasil.

(3) Consultoria, Treinamento, Pesquisa e Desenvolvimento agrícola (Conplant), Rua Francisco Andreo Aledo, 22, 13084-200 Campinas (SP), Brasil.

(4) Universidade Estadual de Campinas (Unicamp), Programa de Pós-graduação em Biologia Vegetal, 13083-862 Campinas (SP), Brasil.

(*) Autora correspondente: alagoa@iac.sp.gov.br

Recebido: 18/abr./2012; Aceito: 4/set./2012

\section{Resumo}

Embora a resposta da fotossíntese de plantas de cana-de-açúcar a estresses ambientais seja conhecida, o acúmulo de fitomassa e a dinâmica de carboidratos de reserva diante da exposição simultânea ao frio e à seca são pouco conhecidos. Este trabalho objetiva investigar o efeito do déficit hídrico e da baixa temperatura radicular, isolados e simultaneamente, no genótipo de cana-de-açúcar IACSP94-2094, considerado tolerante à seca. Como hipótese, consideramos que este genótipo também é tolerante à baixa temperatura radicular, já que baixas temperaturas e déficit hídrico ocorrem simultaneamente no campo. A imposição da restrição hídrica de forma isolada ou simultaneamente à baixa temperatura radicular causou redução do potencial da água na folha e da assimilação de $\mathrm{CO}_{2}$, o que não foi observado nas plantas submetidas apenas à baixa temperatura do substrato. Os teores foliares de carboidratos não estruturais, de sacarose e de amido aumentaram nas plantas sob frio radicular. Nos tratamentos com déficit hídrico, apenas o teor de amido foliar diminuiu. Os estresses radiculares causaram aumento nos teores de açúcares solúveis totais e diminuição no teor de amido nas raízes. Como o acúmulo de fitomassa das plantas não foi afetado, mesmo com a restrição no crescimento radicular nos tratamentos com baixa temperatura do substrato, conclui-se que o genótipo de cana-de-açúcar IACSP94-2094 contém indícios de tolerância à baixa temperatura radicular. A manutenção do crescimento da planta deve estar associada à degradação das reservas de amido foliares e radiculares.

Palavras-chave: Saccharum, seca, baixa temperatura, crescimento, fotossíntese.

\section{Gas exchange and carbohydrate balance in sugarcane plants under root stressful conditions}

\section{Abstract}

Although the photosynthetic responses of sugarcane plants to environmental stresses are well documented, the biomass accumulation and the dynamic of carbohydrate reserves under simultaneous exposure of roots to low temperature and drought are not known. This work aims to investigate the effect of water deficit and low substrate temperature stresses, occurring alone or in combination, on the sugarcane IACSP94-2094, a drought-tolerant genotype. As our hypothesis, we assume that this genotype is also tolerant to low substrate temperature, since low temperatures and water deficit occur simultaneously under field conditions. The water deficit alone or in combination with low substrate temperature caused reductions in leaf water potential and $\mathrm{CO}_{2}$ assimilation, which was not observed in plants subjected only to low substrate temperature. The leaf concentration of non-structural carbohydrates, sucrose and starch increased in plants under root chilling. In plants subjected to water deficit, we noticed decreases in leaf starch concentration. The root stresses caused an increase in the total soluble sugar concentration and reduction in starch concentration in sugarcane roots. As the plant biomass accumulation was not affected, even with the impairment of root growth under low substrate temperature, we conclude that the sugarcane genotype IACSP94-2094 presents evidence of tolerance to low root temperature. The maintenance of plant growth was likely associated with the breakdown of leaf and root reserves of starch.

Key words: Saccharum, drought, low temperature, growth, photosynthesis. 


\section{INTRODUÇÃO}

A água é o principal fator limitante do crescimento da cana-de-açúcar (INMAN-BAMBer e SMith, 2005), reduzindo primeiramente o alongamento e a divisão celular e consequentemente o desenvolvimento das folhas (INMAN-BAMBER, 2004). Alguns genótipos de cana-de-açúcar mostram rápida recuperação após eventos de seca (LANDELl et al., 2005), sendo a tolerância à seca relacionada a mecanismos fisiológicos capazes de manter o crescimento da planta em condição restritiva, tais como fechamento estomático e manutenção da atividade fotossintética (Machado et al., 2009). Também ocorrem mecanismos morfológicos como a manutenção do crescimento radicular quando o déficit hídrico é moderado (Hsiao e Xu, 2000).

Além do déficit hídrico, a temperatura é outro importante elemento ambiental que afeta o crescimento das plantas. A cana-de-açúcar é uma cultura com taxa máxima de crescimento entre 25 e $35^{\circ} \mathrm{C}$ e sob temperatura de $15{ }^{\circ} \mathrm{C}$ já se observa inibição do crescimento vegetativo (Евrahim et al., 1998). Embora a maior parte dos estudos com estresse de frio seja focada em regióes temperadas, com temperaturas abaixo de $10{ }^{\circ} \mathrm{C}$ (Miller et al., 2008), baixas temperaturas também ocorrem com frequência durante o inverno em várias áreas do Estado de São Paulo, condição que ocorre de forma simultânea à deficiência hídrica (Rolım et al., 2007).

Semelhante aos sinais ocorridos durante o estresse hídrico, a baixa temperatura radicular provoca redução da condutância estomática devido a sinais transmitidos pelas raízes (Veselova et al., 2005). Menor fluxo de seiva no floema também foi observado sob frio, com decorrente acúmulo de açúcares solúveis nas folhas, em especial a sacarose (HartT, 1965; Krapp e Stitt, 1995).

Embora as plantas sejam submetidas simultaneamente à baixa temperatura e à restrição hídrica em condição de campo, estudos sobre o efeito de estresses simultâneos são raros na literatura e as respostas de plantas de cana-de-açúcar à exposiçáo simultânea ao frio e à seca são desconhecidas ao considerarmos o acúmulo de fitomassa e a dinâmica de carboidratos de reserva.

Este trabalho objetiva investigar o efeito do déficit hídrico e da baixa temperatura radicular, isolados e simultaneamente, no genótipo de cana-de-açúcar IACSP94-2094, considerado tolerante à seca (Machado et al., 2009). Como hipótese, consideramos que o genótipo IACSP94-2094 também é tolerante à baixa temperatura radicular, uma vez que baixas temperaturas e déficit hídrico ocorrem simultaneamente em condiçóes de campo. O estudo também se propóe a analisar a variação no teor de carboidratos de reserva devido ao frio e à seca, relacionando-a com o acúmulo de fitomassa da planta.

\section{MATERIAL E MÉTODOS}

\section{Local e condições de crescimento}

O experimento foi realizado em casa de vegetaçáo, localizada em Campinas (SP), a $22^{\circ} 54^{\prime} \mathrm{S} ; 47^{\circ} 05^{\prime} \mathrm{O}$; altitude de $674 \mathrm{~m}$, temperatura do ar variando entre 19,3 e $41,9^{\circ} \mathrm{C}$ e radiação fotossinteticamente ativa (Q) chegou a $1500 \mathrm{mmol} \mathrm{m}^{-2} \mathrm{~s}^{-1}$ durante o período experimental. As plantas do genótipo de Saccharum spp. IACSP94-2094, considerado adaptado a ambientes restritivos (LANDELL et al., 2005; MACHADO et al., 2009), foram propagadas vegetativamente em substrato, pela brotação de segmentos de colmo contendo uma gema. Aos 53 dias após o plantio (DAP), as mudas individualizadas foram transferidas para sacos plásticos $(5 \mathrm{~L})$, contendo terra previamente analisada quimicamente e adubada, conforme a recomendação de van RAIJ et al. (1996). Foi realizada adubaçáo foliar quinzenal com ureia $1 \%$ e fosfato-monoamônio 5\%, a partir de 53 DAP até 105 DAP. As plantas foram crescidas com apenas o colmo principal, com remoção dos perfilhos.

Aos 81 DAP, as plantas foram dispostas em caixas de isopor com água para que a temperatura do substrato fosse mantida em torno de $25^{\circ} \mathrm{C}$. As caixas foram fechadas com as tampas sendo cortadas de tal forma a se encaixar ao redor das plantas para haver maior isolamento da temperatura. Aos 105 DAP, iniciaram-se os tratamentos experimentais, sendo a temperatura da água no interior de uma caixa mantida a $25^{\circ} \mathrm{C}$ e em outra, a $15^{\circ} \mathrm{C}$. O resfriamento foi realizado com a adição de água fria e as temperaturas do substrato foram monitoradas com termômetros de máxima e mínima. Para cada temperatura imposta, quatro plantas tiveram a irrigação suspensa e as outras quatro foram irrigadas, mantendo-se o substrato com $80 \%$ da capacidade máxima de armazenamento de água. O controle da irrigação foi feito pela pesagem diária dos sacos plásticos. Os devidos cuidados foram tomados para que as plantas não fossem submetidas à hipoxia nas caixas térmicas, sendo cada planta colocada no interior de um saco plástico sem furos, evitando-se o contato direto do sistema radicular com o meio líquido das caixas.

Além das plantas controle (referência, R) que não foram submetidas a estresse radicular, havia os tratamentos com plantas com temperatura do substrato de $25^{\circ} \mathrm{C}$ e sem irrigação (S); temperatura do substrato de $15^{\circ} \mathrm{C}$ e com irrigação (F); e temperatura do substrato de $15^{\circ} \mathrm{C}$ e sem irrigação (SF). Os tratamentos foram suspensos aos 116 DAP, após onze dias do início, quando a transpiração das plantas sob déficit hídrico atingiu $10 \%$ da transpiração das plantas controle (Liu et al., 2003). As plantas foram reidratadas e mantidas na condição $\mathrm{R}$ para a fase de recuperação, entre 116 e 120 DAP. O teor de água no substrato dos sacos plásticos durante o período experimental foi expresso como a fração de água disponível 
no substrato (FADS), segundo Liu et al. (2003), sendo: FADS $=\left(M_{n}-M_{f}\right) / T A T S$, onde $M_{n}$ é a massa do recipiente com as plantas em uma determinada data; $M_{f}$ é a massa quando a transpiração das plantas sob estresse atingiu $10 \%$ das plantas-referência (116 DAP); TATS é o total de água transpirável do substrato, ou seja, massa dos recipientes com substrato a $80 \%$ da capacidade de campo.

\section{Avaliações biométricas e do status hídrico}

As medidas de matéria seca da parte aérea e das raízes foram feitas pela secagem em estufa de circulação forçada de $\operatorname{ar}\left(55^{\circ} \mathrm{C}\right)$ até massa constante, antes da imposição dos tratamentos (101 DAP) e aos 120 DAP. O crescimento das plantas foi estimado pela diferença da massa da matéria seca entre o início e o final do experimento, considerando o período de 19 dias. A razão entre a massa da matéria seca da parte aérea e da raiz foi calculada.

O potencial da água na folha $\left(\Psi_{\mathrm{w}}\right)$ foi medido na segunda folha totalmente expandida e com a lígula aparente (folha +2 ), com uma câmara de pressão (modelo 3005, Soilmoisture Equipment Corp., EUA). As medidas foram realizadas às $5 \mathrm{~h} 40$ e às $12 \mathrm{~h} 30$, aos $116 \mathrm{DAP}$. A condutância hidráulica da planta $\left(\mathrm{k}_{\mathrm{L}}\right)$ foi estimada conforme Ribeiro et al. (2009), aos 116 DAP.

\section{Trocas gasosas}

As avaliaçôes de trocas gasosas foram feitas aos 116 DAP, no terço médio da primeira folha totalmente expandida e com a lígula aparente (folha +1$)$, com um analisador de gases por infravermelho modelo Li-6400F (Licor, EUA). As variáveis condutância estomática $\left(\mathrm{g}_{\mathrm{s}}\right)$, assimilação de $\mathrm{CO}_{2}\left(\mathrm{P}_{\mathrm{N}}\right)$ e transpiração $(\mathrm{E})$ foram avaliadas e os valores diários integrados de $\mathrm{P}_{\mathrm{N}}\left(\mathrm{P}_{\mathrm{NI}}\right)$ e de $\mathrm{E}\left(\mathrm{E}_{\mathrm{I}}\right)$ calculados a partir da dinâmica diurna das trocas gasosas (avaliada entre $8 \mathrm{~h}$ e $16 \mathrm{~h}$, em intervalos de 2 horas). Nessa ocasiāo, a eficiência diária do uso da água $\left(\mathrm{EUA}=\mathrm{P}_{\mathrm{NI}} / \mathrm{E}_{\mathrm{I}}\right)$ foi estimada. As avaliaçóes foram realizadas sob variação natural da umidade relativa $(48,5 \pm 2,9 \%)$ e da temperatura do ar $\left(35,1 \pm 2,6^{\circ} \mathrm{C}\right)$.A radiação fotossinteticamente ativa (Q) integrada no dia de medida foi de $23,9 \mathrm{~mol} \mathrm{~m}^{-2} \mathrm{~d}^{-1}$ sendo Q máximo de $1200 \mathrm{mmol} \mathrm{m}^{-2} \mathrm{~s}^{-1}$. A diferença de pressão de vapor entre a folha e o ar foi de $2,9 \pm 0,1 \mathrm{kPa}$ e a temperatura foliar de $35,2 \pm 0,2{ }^{\circ} \mathrm{C}$ no dia da avaliação.

\section{Carboidratos}

Amostras de folhas e raízes foram coletadas aos 116 DAP e secas em estufa com circulação forçada de ar $\left(55^{\circ} \mathrm{C}\right)$ até atingirem massa seca constante. A extração e a purificação dos carboidratos foram feitas com solução MCW (metanol:clorofórmio:água), segundo Bieleski e Turner (1966). Os teores de sacarose (SAC), de amido (AMI) e de açúcares solúveis totais (AST) foram determinados de acordo com van Handel (1968), Dubois et al. (1956) e Amaral et al. (2007) respectivamente. O teor de carboidratos metabolizáveis (CNE) foi calculado pela soma de AST e AMI.

\section{Análise dos dados}

O delineamento experimental foi inteiramente casualizado e a causa de variação foi a condição ambiental, i.e., referência $(\mathrm{R})$, baixa temperatura $(\mathrm{F})$, déficit hídrico $(\mathrm{S})$ e baixa temperatura associada ao déficit hídrico (SF). Os resultados foram submetidos à análise de variância, sendo as médias provenientes de três repetiçôes. Quando detectado efeito significativo do ambiente, as médias foram comparadas pelo teste de Tukey a 5\% de probabilidade.

\section{RESULTADOS}

A fração de água disponível no substrato (FADS) das plantas irrigadas dos tratamentos com 15 e $25^{\circ} \mathrm{C}$ do sistema radicular variou ao redor de 0,80 , enquanto nas plantas não irrigadas a FADS decresceu, chegando a zero aos 114 DAP (Figura 1).

Aos $116 \mathrm{DAP}$, a baixa temperatura do substrato não provocou mudanças em $\Psi_{w}$, enquanto os tratamentos com déficit hídrico ( $S$ e $S F$ ) causaram redução de $\Psi_{w}$ na antemanhã e à tarde, quando comparados à referência (Figura 2a). Em comparação ao frio, a ocorrência de

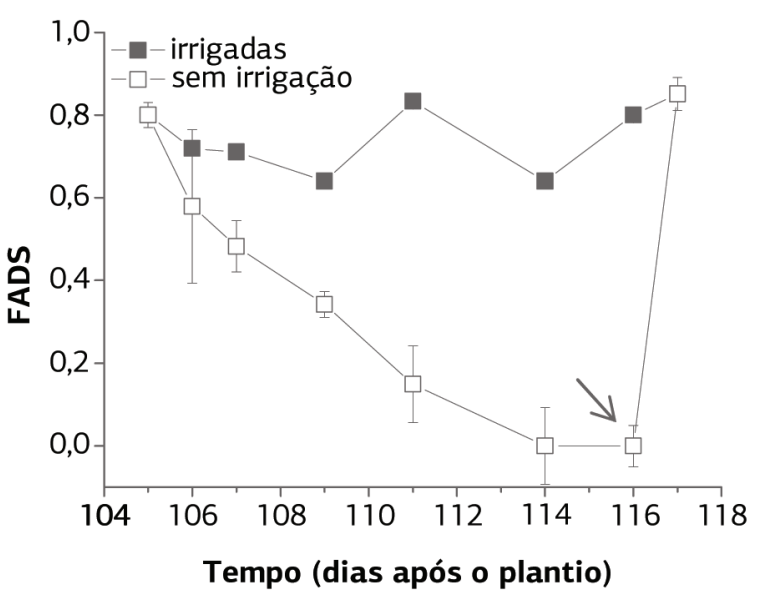

Figura 1. Fração de água disponível no substrato (FADS) durante o período experimental. A rega foi suspensa aos $105 \mathrm{DAP}$ e as plantas foram reidratadas aos 116 DAP (seta). Os dados sem irrigação (quadrados vazios) representam a média entre os tratamentos de déficit hídrico com sistema radicular a $25^{\circ} \mathrm{C}$ e a $15^{\circ} \mathrm{C}$. Valor médio $(\mathrm{n}=6) \pm$ desvio-padrão. 

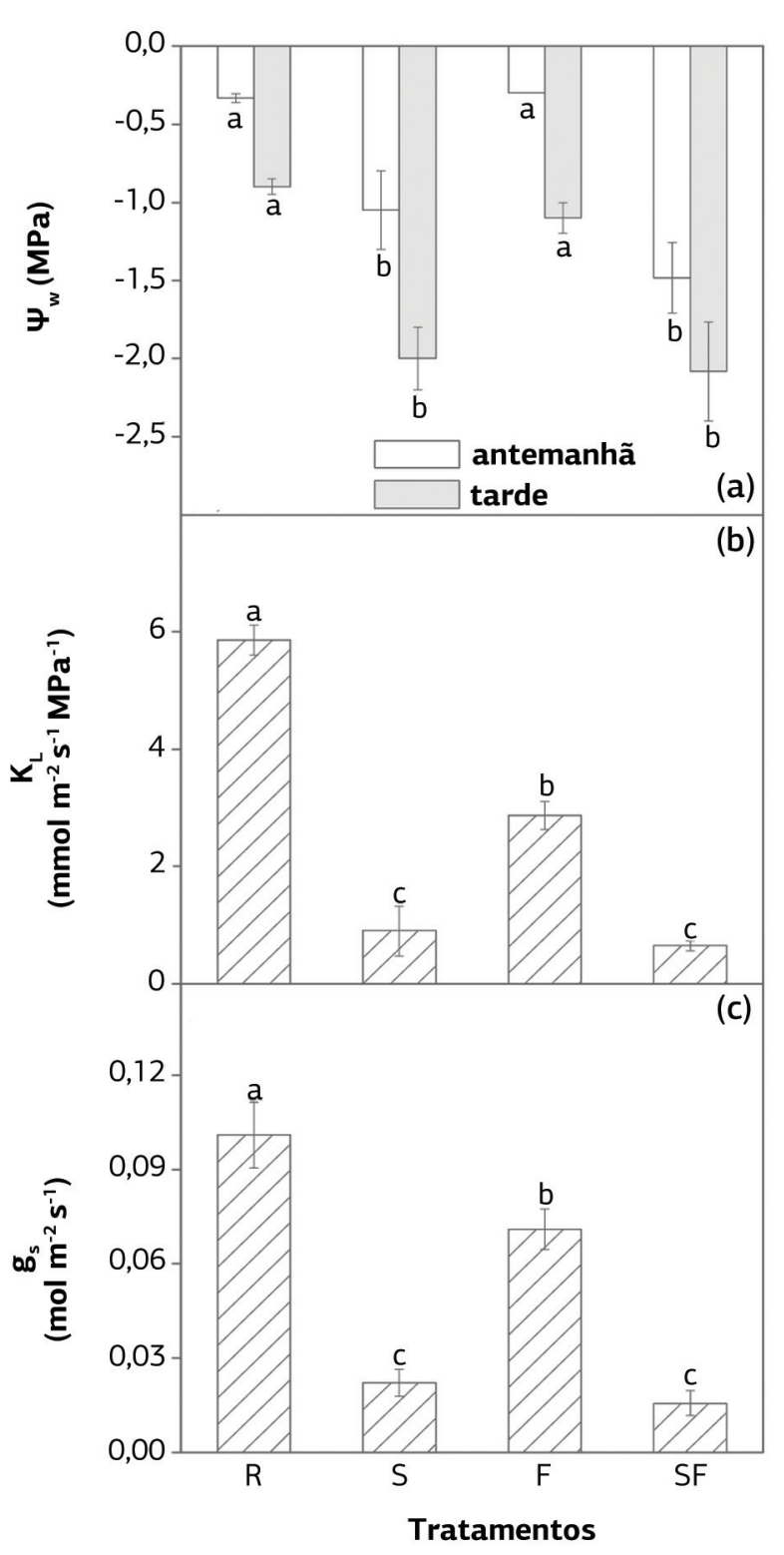

Figura 2. Potencial da água na folha $\left(\Psi_{w}\right.$, em a), condutância hidráulica da planta $\left(\mathrm{k}_{\mathrm{L}}\right.$, em b), e condutância estomática $\left(\mathrm{g}_{\mathrm{s}}\right.$, em c) de plantas de cana-de-açúcar IACSP94-2094 submetidas a tratamentos com temperatura do substrato de $25^{\circ} \mathrm{C}$ e sem irrigaçáo (S); de $15^{\circ} \mathrm{C}$ e com irrigação $(\mathrm{F})$; e de $15^{\circ} \mathrm{C}$ e sem irrigaçáo (SF). As plantas do tratamento - referência $(\mathrm{R})$ foram submetidas à temperatura do substrato de $25^{\circ} \mathrm{C}$ e irrigação. As medidas foram realizadas após 11 dias de tratamento, aos 116 DAP. Valor médio $(\mathrm{n}=3) \pm$ desvio-padrão. Letras iguais não são estatisticamente diferentes pelo teste de Tukey a 5\% de probabilidade.

déficit hídrico causou maior impacto na $\mathrm{k}_{\mathrm{L}}$. Enquanto a $k_{L}$ foi reduzida em $87 \%$ nos tratamentos $S$ e SF, nas plantas submetidas apenas ao frio radicular houve redução de $50 \%$ em relação à referência (Figura $2 \mathrm{~b}$ ). Seguindo o mesmo padrão de resposta, a condutância estomática foi reduzida em $81 \%$ nos tratamentos com déficit hídrico (S e SF) e em apenas 29\% no tratamento F (Figura 2c).

Em relação à referência, o déficit hídrico nos tratamentos S e SF causou redução de $92 \%$ na $\mathrm{P}_{\mathrm{NI}}$ e de $82 \%$ na $\mathrm{E}_{\mathrm{I}}$ após onze dias de tratamento (Figuras 3a,b). Já nas plantas submetidas à baixa temperatura radicular isoladamente não se observou variação significativa de $\mathrm{P}_{\mathrm{NI}}$ e $\mathrm{E}_{\mathrm{r}}$. Considerando a EUA, houve redução significativa apenas nas plantas dos tratamentos $S$ e SF (Figura 3c).

$\mathrm{O}$ teor foliar de CNE no tratamento $\mathrm{S}$ se manteve semelhante ao da referência, mas sob baixa temperatura radicular ocorreu aumento de 38\% (Figura 4a). O teor foliar de AST não foi afetado pelos tratamentos (Figura 4b). O teor de SAC não foi alterado sob déficit hídrico, mas o

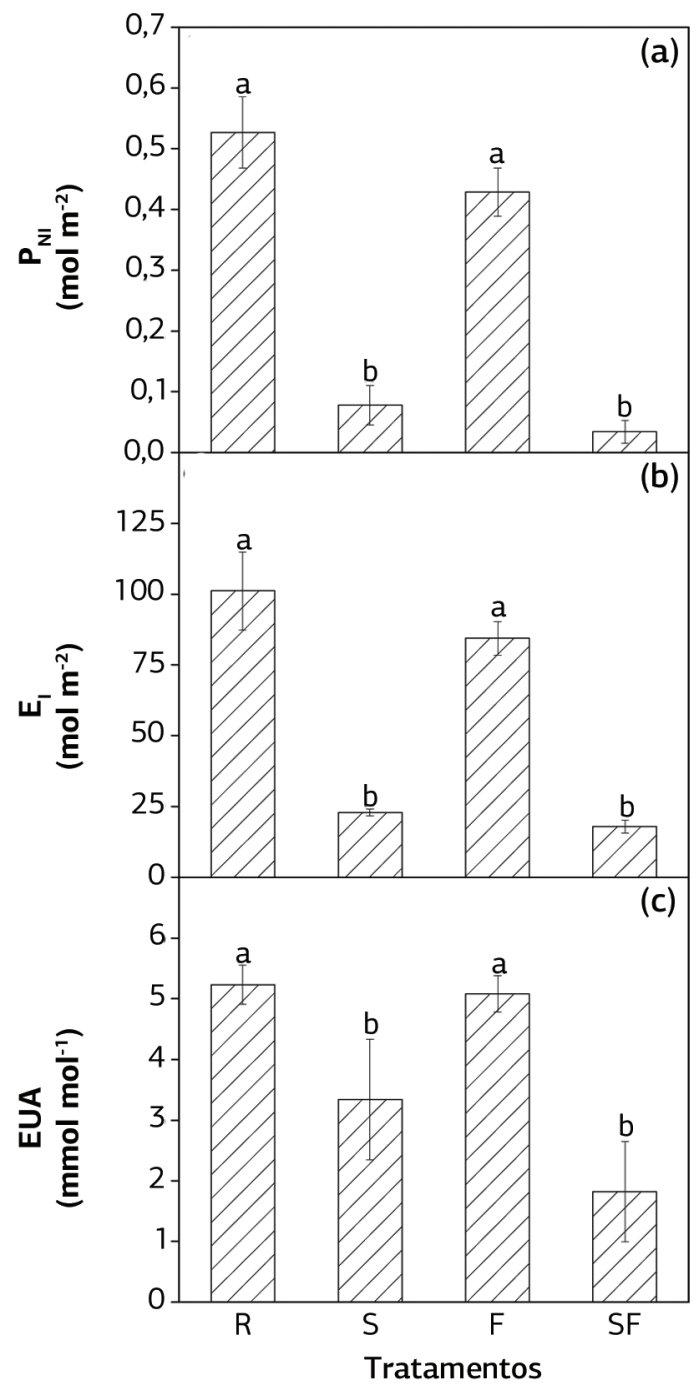

Figura 3. Assimilação diurna de $\mathrm{CO}_{2}\left(\mathrm{P}_{\mathrm{NI}}\right.$ em a), da transpiração diurna $\left(\mathrm{E}_{\mathrm{l}}\right.$, em $\mathrm{b}$ ) e da eficiência diurna do uso da água (EUA, em c) diárias das plantas de cana-de-açúcar IACSP94-2094 submetidas a tratamentos com temperatura do substrato de $25^{\circ} \mathrm{C}$ e sem irrigação (S); de $15^{\circ} \mathrm{C}$ e com irrigação (F); e de $15^{\circ} \mathrm{C}$ e sem irrigação (SF). As plantas do tratamento-referência $(\mathrm{R})$ foram submetidas à temperatura do substrato de $25{ }^{\circ} \mathrm{C}$ e irrigação. As medidas foram realizadas após 11 dias de tratamento, aos 116 DAP. Os valores de $\mathrm{P}_{\mathrm{NI}}$ e $\mathrm{E}_{\mathrm{I}}$ referem-se à integração dos valores de assimilação de $\mathrm{CO}_{2}$ e de transpiração medidos entre 7 h e 17 h, em intervalos de 2 horas. Valor médio $(n=3) \pm$ desvio-padrão. Letras iguais não são estatisticamente diferentes pelo teste de Tukey a $5 \%$ de probabilidade. 
frio radicular causou aumento de $86 \%$ neste carboidrato (Figura 4c). O teor foliar de AMI diminuiu em 53\% nos tratamentos S e SF. Assim como observado para SAC, o frio radicular aumentou o teor de AMI em 87\% (Figura 4d).

Nas raízes, houve aumento de $63 \%$ nos teores de $\mathrm{CNE}$ apenas no tratamento $S$ quando comparado à referência (Figura 4e). Os teores de AST nas raízes foram significativamente aumentados (entre duas e três vezes) nos tratamentos com estresse radicular (Figura 4f). Enquanto no teor de SAC nas raízes não houve alteraçôes significativas (Figura 4g), os teores de AMI diminuíram em $28 \%$ nos tratamentos $\mathrm{S}$ e $\mathrm{F}$ e em $68 \%$ no tratamento SF (Figura 4h).

O crescimento da planta (Figura 5a) e o crescimento da parte aérea (Figura 5b) não foram significativamente afetados pelos tratamentos com frio e déficit hídrico, mesmo com a restrição de $34 \%$ no crescimento radicular nos tratamentos com baixa temperatura do substrato
(Figura 5c). Nas plantas desses tratamentos, observou-se maior razão parte aérea/raiz (Figura $5 \mathrm{~d}$ ).

\section{DISCUSSÃO}

\section{Relações hídricas e trocas gasosas}

Neste estudo, nota-se que a imposição da restrição hídrica, da baixa temperatura do substrato ou da combinaçáo desses fatores não afetou o crescimento das plantas (Figura 5a), mas causou significativa variação nas trocas gasosas foliares e no teor de carboidratos foliares e radiculares (Figuras 3 e 4 ).

O déficit hídrico afetou o status hídrico das plantas, causando diminuição de $\Psi_{\mathrm{w}}$ e, portanto, sugerindo uma sinalização hidráulica que levou ao fechamento estomático (Figura 2a,c). Como uma provável consequência, a

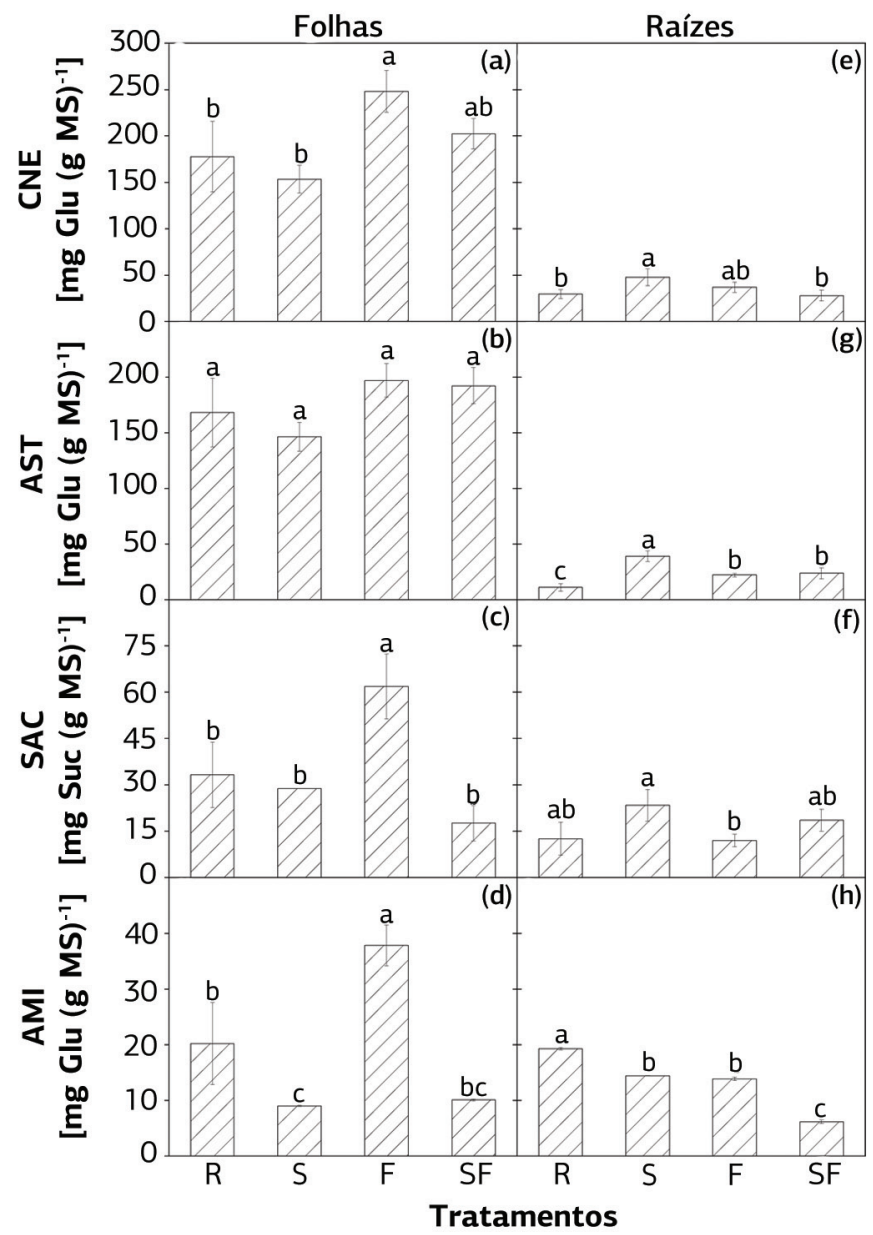

Figura 4. Teores de carboidratos metabolizáveis (CNE, em a,e), de carboidratos solúveis totais (AST, em b,f), de sacarose (SAC, em c,g), e de amido (AMI, em d,h) nas folhas (a-d) e nas raízes (e-h) de plantas de cana-de-açúcar IACSP94-2094 submetidas a tratamentos com temperatura do substrato de $25^{\circ} \mathrm{C}$ e sem irrigação $(\mathrm{S})$; de $15^{\circ} \mathrm{C}$ e com irrigação $(\mathrm{F})$; e de $15^{\circ} \mathrm{C}$ e sem irrigação $(\mathrm{SF})$. As plantas do tratamento-referência (R) foram submetidas à temperatura do substrato de $25^{\circ} \mathrm{C}$ e irrigação. As medidas foram realizadas após 11 dias de tratamento, aos $116 \mathrm{DAP}$. Valor médio ( $\mathrm{n}=3) \pm$ desvio-padrão. Letras iguais nắo são estatisticamente diferentes pelo teste de Tukey a $5 \%$ de probabilidade. 
diminuição da quantidade de água nas folhas aumentaria indiretamente a concentração de $\mathrm{ABA}$, já presente na parte aérea próximo às células-guarda, o que também poderia reduzir a abertura estomática (TARdieu e Davies, 1992; Christmann et al., 2007). O fechamento estomático causou significativa diminuição na $\mathrm{P}_{\mathrm{NI}}$ e na $\mathrm{E}_{\mathrm{I}}$ em ambos os tratamentos com seca (Figuras 3a,b). A diminuição de $\mathrm{g}_{\mathrm{s}}$ nesses tratamentos pode ser uma estratégia para diminuir a perda de água pela transpiraçấo (INMAN-BAMBER e Smith, 2005; InMAN-BAmber et al., 2008), sendo, portanto, um mecanismo de resistência à seca.

As plantas submetidas a estresses radiculares tiveram diminuição da $\mathrm{k}_{\mathrm{L}}$ (Figura 2b). Podemos considerar que a redução da $\mathrm{k}_{\mathrm{L}}$ poderia reduzir a suscetibilidade da planta à desidratação, sendo um mecanismo importante em condiçôes de restrição hídrica, uma vez que haveria menor perda de água para atmosfera pela maior resistência interna ao fluxo de água (Hachez et al., 2012). Ainda, pode-se argumentar que tal estratégia foi efetiva uma vez que o crescimento das plantas não foi comprometido. Embora o frio radicular não tenha causado alteraçōes no status hídrico das folhas, houve menor $\mathrm{k}_{\mathrm{L}}$ (Figura 2a,b). Esses dados sugerem que a provável sinalização química proveniente das raízes devido ao frio radicular causou o fechamento parcial dos estômatos, impedindo variaçáo significativa de $Y_{w}$. A redução de $g_{s}$ em condição de baixa temperatura seria uma resposta eficiente para evitar a desidratação da parte aérea, visto que o suprimento de água pelas raízes diminui (WiLkinson et al., 2001).

Em relação à sinalização química, o declínio no teor de citocinina na parte aérea foi responsável pelo fechamento estomático em trigo sob temperaturas próximas a $7^{\circ} \mathrm{C}$ (Veselova et al., 2005). Porém, em temperaturas próximas a $12{ }^{\circ} \mathrm{C}$, o aumento do teor de ácido abscísico derivado das raízes na parte aérea pode ser o principal responsável pelo fechamento estomático (Smith e Dale, 1988). Estudos com plantas de diferentes espécies indicam que o aumento da concentração de ácido abscísico na parte aérea e a rapidez com que esse processo ocorre sáo características presentes em genótipos tolerantes à baixa temperatura (Li et al., 2002; Pagter et al., 2008).

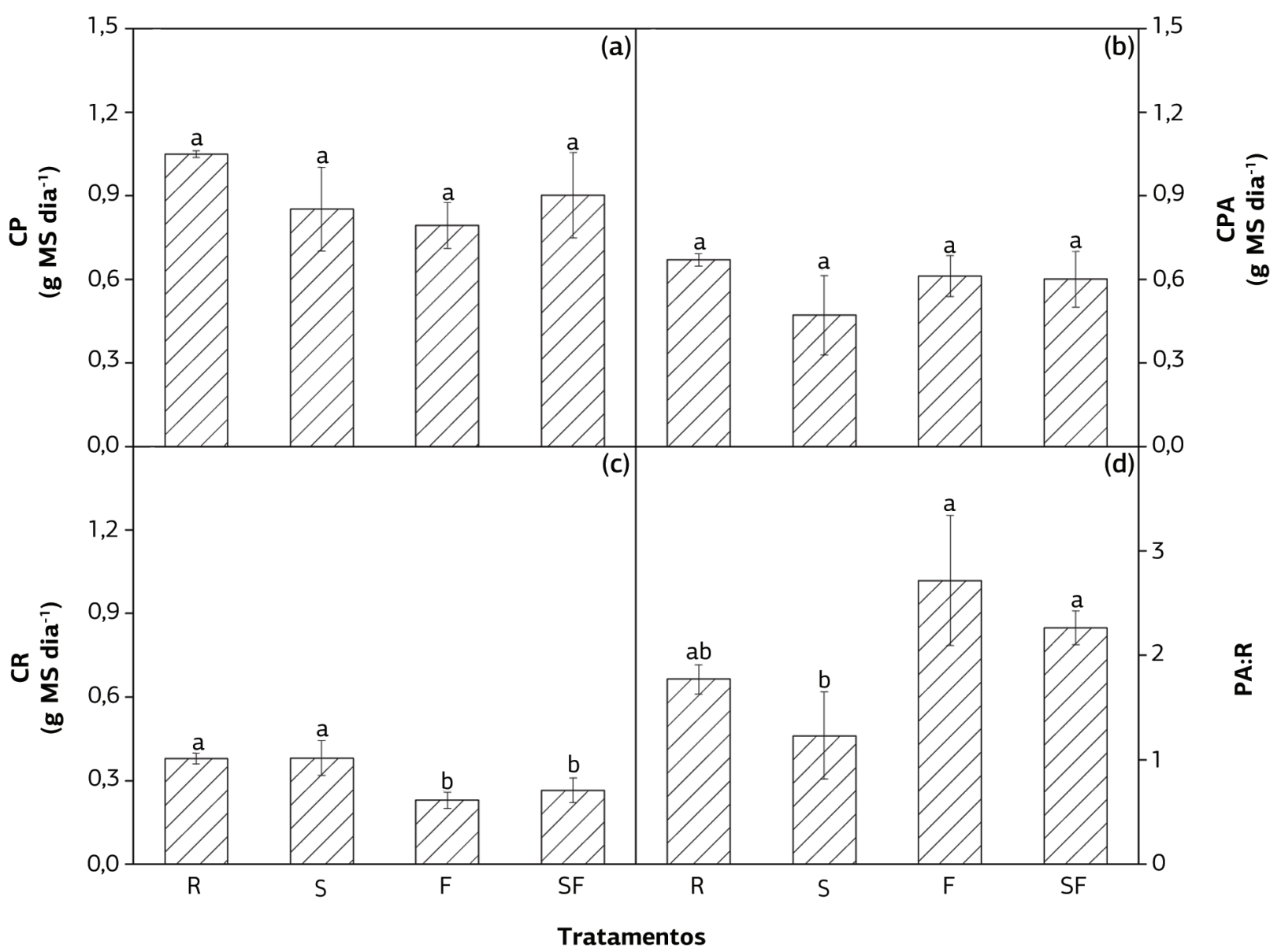

Figura 5. Crescimento das plantas (CP, em a), da parte aérea (CPA, em b), das raízes (CR, em c) e razáo parte aérea/raiz (PA:R, em d) de plantas de cana-de-açúcar IACSP94-2094 submetidas a tratamentos com temperatura do substrato de $25^{\circ} \mathrm{C}$ e sem irrigação $(\mathrm{S})$; de $15^{\circ} \mathrm{C}$ e com irrigação (F); de $15^{\circ} \mathrm{C}$ e sem irrigação (SF). As plantas do tratamento-referência (R) foram submetidas à temperatura do substrato de $25^{\circ} \mathrm{C}$ e irrigaçáo. Valor médio ( $\mathrm{n}=3) \pm$ desvio-padrão. Letras iguais não são estatisticamente diferentes pelo teste de Tukey a $5 \%$ de probabilidade. 


\section{Suprimento de carbono e crescimento}

O déficit hídrico isolado ou simultâneo ao frio limitou a fotossíntese pelo fechamento estomático (Figuras $2 \mathrm{c}$ e 3a) e acarretou menor disponibilidade de $\mathrm{CO}_{2}$ para a produção de carboidratos (Chaves et al., 2002). Mesmo com o comprometimento da assimilação de $\mathrm{CO}_{2}$ sob déficit hídrico (Figura 3a), os teores de SAC, AST e CNE nas folhas mantiveram-se semelhantes aos das plantas-referência (Figura 4a-c). Como o teor foliar de AMI foi reduzido sob déficit hídrico (Figura 4d), pode-se sugerir que o carbono utilizado para manter o nível de carboidratos solúveis nas folhas foi proveniente da hidrólise do amido. De fato, o consumo de AMI seria uma resposta inicial à seca permitindo a manutenção do suprimento de carbono em uma condição de reduzida fixação de $\mathrm{CO}_{2}$ atmosférico (KAKANI et al., 2011). A reduçáo no teor de AMI nos tratamentos $S$ e SF também poderia ser consequência da menor síntese de amido sob condiçôes de estresse hídrico (Chaves, 1991; Pinheiro e Chaves, 2011).

Diferente dos tratamentos com suspensão da irrigação, o frio isoladamente provocou aumento de CNE nas folhas, induzido pelo aumento de AMI (Figura 4a,d). O acúmulo desse carboidrato nas folhas ocorre quando há paralisação na exportaçáo de triose-fosfato do cloroplasto e está normalmente associado à redução da força de dreno e dos teores de SAC no tecido (Paul e Pellny, 2003; Ainsworth e Bush, 2011). No entanto, pode-se observar que o teor de SAC aumentou nas folhas (Figura 4c) e que aparentemente houve comprometimento do transporte via floema quando o frio ocorreu isoladamente. Quando a exportaçấo de SAC a partir das folhas torna-se inibida, os açúcares se acumulam nas folhas e ocasionam aumento da expressão de genes envolvidos no armazenamento de carboidratos (Paul e Pellny, 2003; Ainsworth e Bush, 2011). Em cana-de-açúcar, o transporte de açúcares via floema é bastante sensível à baixa temperatura (НARTT, 1965), sendo mais afetado do que a atividade fotossintética (ЕвRAнiм et al., 1998; Du e Nose, 2002). Considerando a relação fonte-dreno, sabe-se que a fotossíntese em cana-de-açúcar torna-se inibida com o aumento da concentraçáo de hexoses nas folhas-fonte (McCormick et al., 2008). Logo, poderíamos mencionar que o acúmulo de AMI, ao invés de hexoses em condiçôes limitantes, seria benéfico uma vez que as plantas teriam uma reserva de carboidratos na fase de retomada do crescimento e náo haveria o potencial efeito repressor das hexoses sobre a fotossíntese durante a limitação ambiental.

Nas raízes, houve redução da concentração de AMI em todos os tratamentos e aumento de AST (Figura 4f,h). Como a concentração de SAC no sistema radicular das plantas submetidas a condiçôes estressantes não foi afetada (Figura 4g), pode-se sugerir que outros açúcares solúveis foram responsáveis pelo aumento em AST, como a trealose. A trealose é um carboidrato presente em plantas superiores e seu acúmulo costuma ocorrer em espécies resistentes à seca (EL-BASHiti et al., 2005; PAUL et al., 2008; QueIroz et al., 2011). O aumento de AST do sistema radicular pode ter efeito osmótico e contribuir para a manutenção do status hídrico e turgor das raízes (Hare et al., 1998), tendo como consequência a manutenção do crescimento do sistema radicular nas plantas do tratamento $S$ (Figura 5c). Nota-se que a influência da baixa temperatura prevaleceu em relaçáo aos efeitos da falta de água. De acordo com os resultados, a ocorrência de frio no sistema radicular inibe o acúmulo de carboidratos solúveis nas raízes, impedindo o potencial efeito benéfico desses carboidratos em termos de ajuste osmótico. Essa resposta associada à redução no fornecimento de carbono via fotossíntese teve como consequência a redução do crescimento radicular sob frio (tratamentos F e SF) e aumento da relação parte aérea: raiz (Figura 5).

Quando considerado o crescimento das plantas, observou-se que as raízes foram afetadas pela baixa temperatura do substrato. Os tratamentos F e SF causaram diminuição significativa na massa seca das raízes, mas a massa seca das folhas e das plantas não foi afetada (Figuras 5a,b,c). Aparentemente, a manutenção do crescimento das plantas sob estresses radiculares de seca e frio, isolados ou combinados, ocorreu à custa das reservas de carbono na forma de amido (Figuras 4d,h e 5). As plantas de cana-de-açúcar têm habito semiperene, sendo submetidas a variaçôes consideráveis de recursos ambientais, tais como água e energia solar ao longo do ciclo de cultivo. Nesse contexto, a deficiência hídrica e a baixa temperatura associada à baixa disponibilidade energética ocorrem naturalmente durante o inverno e as plantas devem ser aptas a superar essas condiçôes adversas, especialmente as consideradas tolerantes.

Conclui-se que o genótipo de cana-de-açúcar IACSP94-2094 contém indícios de tolerância à baixa temperatura radicular, evidenciado pela manutenção do crescimento das plantas sob déficit hídrico, baixa temperatura radicular e sob ambas as condições simultâneas (frio e deficiência hídrica). Embora as condiçôes adversas tenham reduzido a fotossíntese das plantas, o suprimento de carbono e a manutenção dos níveis de carboidratos solúveis nas folhas e raízes devem estar associados à degradação das reservas de amido.

\section{AGRADECIMENTOS}

Os autores agradecem à CAPES pela concessão de bolsa de mestrado à primeira autora; à FAPESP e ao CNPq pelo financiamento do projeto temático BIOEN (Proc. n. ${ }^{\circ}$ 2008/57495-3); ao Centro Avançado de Pesquisa Tecnológica do Agronegócio de Cana, IAC, Ribeirão Preto (SP), e pela ajuda dos pesquisadores e colegas de trabalho. 


\section{REFERÊNCIAS}

AINSWORTH, E.A.; BUSH, D.R. Carbohydrate export from the leaf: a highly regulated process and target to enhance photosynthesis and productivity. Plant Physiology, v.155, p.64-69, 2011.

AMARAL, L.I.V.; GASPAR, M.; COSTA, P.M.F.; AIDAR, M.P.M.; BUCKERIDGE, M.S. Novo método enzimático rápido e sensível de extraçáo e dosagem de amido em materiais vegetais. Hoehnea, v.34, p.425-431, 2007.

BIELESKI, R.L.; TURNER, A. Separation and estimation of amino acids in crude plant extracts by thin-layer electrophoresis and chromatography. Analytical Biochemistry, v.17, p.278293, 1966.

CHAVES, M.M. Effects of water deficits on carbon assimilation. Journal of Experimental Botany, v.42, p.1-16, 1991.

CHAVES, M.M.; PEREIRA, J.S.; MAROCO, J.; RODRIGUES, M.L.; RICARDO, C.P.P., OSÓRIO, M.L.; CARVALHO, I.; FARIA, T.; PINHEIRO, C. How plants cope with water stress in the field: Photosynthesis and growth. Annals of Botany, v.89, p. 907-916, 2002.

CHRISTMANN, A.; WEILER, E.W.; STEUDLE, E.; GRILL, E.A hydraulic signal in root-to-shoot signaling of water shortage. The Plant Journal, v.52, p.167-174, 2007.

DU, Y.C.; NOSE, A. Effects of chilling temperature on the activity of enzymes of sucrose synthesis and the accumulation of saccharides in leaves of three sugarcane cultivars differing in cold sensitivity. Photosynthetica, v.40, p.389-395, 2002.

DUBOIS, M.; GILLES, K.A.; HAMILTON, J.K.; REBERS, P.A.; SMITH, F. Colorimetric method for determination of sugars and related substances. Analytical Chemistry, v.28, p.350-356, 1956.

EBRAHIM, M.K.H.; VOGG, G.; OSMAN, M.N.E.H; KOMOR, E. Photosynthetic performance and adaptation of sugarcane at suboptimal temperatures. Journal of Plant Physiology, v.153, p. 587-592, 1998.

EL-BASHITI, T.; HAMAMCI, H.; ÖKTEM, H.A.; YÜCEL, M. Biochemical analysis of trehalose and its metabolizing enzymes in wheat under abiotic stress conditions. Plant Science, v.169, p.47-54, 2005.

HACHEZ, C.; VESELOV, D.; YE, Q.; REINHARDT, H.; KNIPFER, T.; FRICKE, W.; CHAUMONT, F. Short-term control of maize cell and root water permeability through plasma membrane aquaporin isoforms. Plant, Cell and Environment, v.35, p.185-198, 2012.

HARE, P.D.; CRESS, W.A.; STADEN, J. van. Dissecting the roles of osmolyte accumulation during stress. Plant, Cell and Environment, v.21, p.535-553, 1998.

HARTT, C.E. The effect of temperature upon translocation of $\mathrm{C}^{14}$ in sugarcane. Plant Physiology, v.40, p.74-81, 1965.

HSIAO, T.C.; XU, L.K. Sensitivity of growth of roots versus leaves to water stress: biophysical analysis and relation to water transport. Journal of Experimental Botany, v.51, p.1595-1616, 2000.
INMAN-BAMBER, N.G. Sugarcane water stress criteria for irrigation and drying off. Field Crops Research, v.89, p.107$122,2004$.

INMAN-BAMBER, N.G.; SMITH, D.M. Water relations in sugarcane and response to water deficits. Field Crops Research, v.92, p.185-202, 2005.

INMAN-BAMBER, N.G.; BONNETT, G.D; SPILLMAN, M.F.; HEWITT, M.L.; JACKSON, J. Increasing sucrose accumulation in sugarcane by manipulating leaf extension and photosynthesis with irrigation. Australian Journal of Agricultural Research, v.59, p.13-26, 2008.

KAKANI, V.G.; VU, J.C.V.; ALLEN Jr., L.H.; BOOTE, K.J. Leaf photosynthesis and carbohydrates of $\mathrm{CO}_{2}$-enriched maize and grain sorghum exposed to a short period of soil water deficit during vegetative development. Journal of Plant Physiology, v.168, p.2169-2176, 2011.

KRAPP, A.; STITT, M. An evaluation of direct and indirect mechanisms for the "sink-regulation" of photosynthesis in spinach: changes in gas exchange, carbohydrates, metabolites, enzyme activities and steady-state transcript levels after cold-girdling source leaves. Planta, v.195, p.313-323, 1995.

LANDELL, M.G.A.; CAMPANA, M.P.; FIGUEIREDO, P.; VASCONCELOS, A.C.M; XAVIER, M.A.; BIDOIA, M.A.P.; PRADO, H.; SILVA, M.A.; DINARDO-MIRANDA, L.L.; SANTOS, A.S.; PERECIN, D.; ROSSETTO, R.; SILVA, D.N.; MARTINS, A.L.M; GALLO, P.B.; KANTACK, R.A.D.; CAVICHIOLI, J.C.; VEIGA FILHO, A.A.; ANJOS, I.A; AZANIA, C.A.M.; PINTO, L.R.; SOUZA, S.A.C.D. Variedades de cana-de-açúcar para o Centro-Sul do Brasil. Campinas: Instituto Agronômico, 2005.33p. (Boletim Técnico, 197)

LI, C.; PUHAKAINEN, T.; WELLING, A.; VIHERÄ-AARNIO, A.; ERNSTSEN, A.; JUNTTILA, O.; HEINO, P.; PAIVA, E.T. Cold acclimation in silver birch (Betulapendula). Development of freezing tolerance in different tissues and climatic ecotypes. Physiologia Plantarum, v.116, p.478-488, 2002.

LIU, F.; JENSEN, C.R.; ANDERSEN, M.N. Hydraulic and chemical signals in the control of leaf expansion and stomatal conductance in soybean exposed to drought stress. Functional Plant Biology, v.30, p.65-73, 2003.

MACHADO, R.S.; RIBEIRO, R.V.; MARCHIORI, P.E.R.; MACHADO, D.F.S.P.; MACHADO, E.C.; LANDELL, M.G. de A. Respostas biométricas e fisiológicas ao déficit hídrico em canade-açúcar em diferentes fases fenológicas. Pesquisa Agropecuária Brasileira, v.44, p.1575-1582, 2009.

McCORMICK, A.J.; CRAMER, M.D.; WATT, D.A. Changes in photosynthesis rates and gene expression of leaves during a source-sink perturbation in sugarcane. Annals of Botany, v.101, p.89-102, 2008.

MILlER, G.; SHULAEV, V.; MITTLER, R. Reactive oxygen signaling and abiotic stress. Physiologia Plantarum, v.133, p.481489, 2008.

PAGTER, M.; LIU, F.; JENSEN, C.R.; PETERSEN, K.K Effects of chilling temperatures and short photoperiod on 
PSII function, sugar concentrations and xylem sap ABA concentrations in two Hydrangea species. Plant Science, v.175, p. 547-555, 2008.

PAUL, M.J.; PELLNY, T.K. Carbon metabolite feedback regulation of leaf photosynthesis and development. Journal of Experimental Botany, v.54, p.539-547, 2003.

PAUL, M.J.; PRIMAVESI, L.F.; JHURREEA, D.; ZHANG, Y. Trehalose metabolism and signaling. Annual Review of Plant Biology, v.59, p.417-441, 2008.

PINHEIRO, C.; CHAVES, M.M. Photosynthesis and drought: can we make metabolic connections from available data? Journal of Experimental Botany, v.62, p.869-882, 2011.

QUEIROZ, R.J.B.; SANTOS, D.M.M.; FERRAUDO, A.S.; CARLIN, S.D.; SILVA, M.A. Biochemical and physiological responses of sugarcane cultivars to soil water deficiencies. Scientia Agricola, v.68, p.469-476, 2011.

RIBEIRO, R.V.; MACHADO, E.C.; SANTOS, M.G.; OLIVEIRA, R.F. Photosynthesis and water relations of wellwatered orange plants as affected by winter and summer conditions. Photosynthetica, v.47, p.215-222, 2009.

ROLIM, G.S.; CAMARGO, M.B.P.; LANIA, D.G.; MORAES, J.F.L. Classificação climática de Köppen e de Thornthwaite e sua aplicabilidade na determinação de zonas agroclimáticas para o Estado de São Paulo. Bragantia, v.66, p.711-720, 2007.
SMITH, P.; DALE, J.E. The effect of root cooling and excision treatments on the growth of primary leaves of Phaseolus vulgaris L. rapid and reversible increases in abscisic acid content. New Phytologist, v.110, p.293-300, 1988.

TARDIEU, F.; DAVIES, W.J. Stomatal response to abscisic acid is a function of current plant water status. Plant Physiology, v.98, p. $540-545,1992$.

HANDEL, E. van. Direct microdetermination of sucrose. Analytical Biochemistry, v.22, p. 280-283, 1968.

RAIJ, B. van; CANTARELLA, H.; SPIRONELLO, A.; PENATTI, C.P.; MORELLI, J.L.; FILHO ORLANDO, J.; LANDELL, M.G.A.; ROSSETO, R. Cana-de-açúcar. In: RAIJ, B. van; CANTARELLA, H.; QUAGGLIO, J.A.; FURLANI, A.M.C. (Ed.). Recomendações de adubação e calagem para o Estado de São Paulo. Campinas: Instituto Agronômico, 1996. p.237-239.

VESELOVA, S.V.; FARHUTDINOV, R.G.; VESELOV, S.Y.; KUDOYAROVA, G.R.; VESELOV, D.S.; HARTUNG, W.The effect of root cooling on hormone content, leaf conductance and root hydraulic conductivity of durum wheat seedlings (Triticum durum L.). Journal of Plant Physiology, v.162, p.21-26, 2005.

WILKINSON, S.; CLEPHAN, A.L.; DAVIES, W.J. Rapid low temperature-induced stomatal closure occurs in cold-tolerant Commelinacommunis leaves but not in cold-sensitive Tobacco leaves, via a mechanism that involves apoplastic calcium but not abscisic acid. Plant Physiology, v.126, p.1566-1578, 2001. 